\title{
Suppression of $N$-Methyl- $N$-Nitrosourea-Induced Retinal Damage in Mice by Oligonol, an Oligomerized Polyphenol Formulation
}

\author{
Jun Kisugi', Miwako Nasui², Koji Wakame³, Jun Takanari³, Masatoshi Yamazaki', \\ Satoru Yui ${ }^{1}$ \\ ${ }^{1}$ Laboratory of Host Defense, Department of Pharma-Sciences, Teikyo University, Tokyo, Japan \\ ${ }^{2}$ Laboratory of Basic Biology, Department of Pharma-Sciences, Teikyo University, Tokyo, Japan \\ ${ }^{3}$ Amino Up Chemical Co., Ltd., Sapporo, Japan \\ Email: sat-yui@pharm.teikyo-u.ac.jp
}

Received 12 February 2014; revised 15 March 2014; accepted 23 March 2014

Copyright (C) 2014 by authors and Scientific Research Publishing Inc.

This work is licensed under the Creative Commons Attribution International License (CC BY).

http://creativecommons.org/licenses/by/4.0/

(c) (i) Open Access

\begin{abstract}
Oligonol is a lychee fruit-derived functional food that contains oligomerized polyphenol compounds. Oligonol exhibits a number of beneficial biological effects, primarily due to its antioxidant activity. Retinitis pigmentosa (RP) is an inherited chronic degenerative disease affecting retinal photoreceptor cells. There is currently no effective therapy capable of stopping or reversing the progression of the disease. In RP, apoptosis of photoreceptor cells resulting from oxidative damage is considered to be the final common pathway. In this report, we present an evaluation of the suppressive activity of Oligonol against $N$-methyl- $N$-nitrosourea (MNU)-induced retinal damage in mice, which is a commonly used animal model of RP. Both intraperitoneal and oral administration of Oligonol reduced the loss of photoreceptor cells 7 days after MNU injection, as evaluated by histological staining. Photoreceptor cells derived from MNU-treated mice exhibited increased TUNELpositive staining, suggesting increased DNA fragmentation, a hallmark of apoptosis. Oligonol treatment reduced the number of TUNEL-positive cells. Additionally, Oligonol suppressed MNUinduced retinal production of 8-hydroxydeoxyguanosine (8-0HdG), a marker of oxidative stress. Moreover, Oligonol attenuated the MNU-induced decrease in the visual activity of mice, as evaluated by the visual cliff test. Oligonol, therefore, effectively suppresses NMU-induced retinal degeneration.
\end{abstract}

\section{Keywords}

Oligonol; Oligomerized Polyphenols; Retinitis Pigmentosa; $N$-Methyl- $N$-Nitrosourea; Retinal Degeneration; Antioxidant 


\section{Introduction}

Retinitis pigmentosa (RP) is an inherited eye disease characterized by a slowly progressive retinal degeneration. The main symptoms are decreased vision at night and loss of peripheral vision in the early stages of the disease, occasionally leading to blindness in the later stages, as reviewed in [1]. It is estimated that approximately 1 out of 4000 people is afflicted by RP [1]. Pathologically, degeneration of photoreceptor cells is commonly observed, usually starting with the death of rod cells, followed by degeneration of cone cells [1]. Mutations in over 100 genes considered causative or related to RP have been reported [2], accounting for the differences in disease progression and outcome between the patients and making treatment difficult. There are no effective treatments currently recognized that are capable of arresting the progression of the disease or reversing the condition. Although gene therapy and stem cell implants are expected to start a new era in RP treatment in the future [3]-[5], effective therapy aimed at the suppression of photoreceptor degeneration is urgently required.

To date, therapeutic approaches using vitamins A and E, or vitamin A in combination with nutritional supplements docosahexaenoic acid or lutein have been suggested to suppress retinal degeneration [6] [7]. Death of the photoreceptor cells was proposed to be caused by oxidative damage [8] [9]. Oral administration of the antioxidant $N$-acetylcysteine was reported to effectively slow the progression photoreceptor cell death in animal models of RP [10]. Since it was also suggested that all types of RP converge on the common pathway of apoptotic photoreceptor cell death, anti-apoptotic compounds were postulated to be potentially useful for the treatment of RP [11]. However, considering the extremely long duration of this disease, pharmacological or nutritional interventions need to be not only effective, but also safe for long term use to be applicable in slowing the progression of the disease.

Flavonoids are plant polyphenols that exhibit a variety of biological activities, including antioxidative, antiinflammatory, anti-carcinogenic, anti-allergic, anti-bacterial, and anti-thrombotic properties [12]-[16]. Among flavonoid compounds, proanthocyanidins exhibit stronger protective activity against free radical-induced lipid peroxidation and DNA damage, as compared to vitamins $\mathrm{C}$, E, and $\beta$-carotene [17]. However, proanthocyanidins are found as polymers in crude plant materials [18], which may lower their absorption and bioavailability following ingestion.

Oligonol is a commercially available, manufactured dietary ingredient containing oligomerized polyphenols, namely monomeric and oligomeric proanthocyanidins, derived from lychee and other fruits [19] by a fragmentation of proanthocyanidine polymers from crude fruit extracts [20]. Such oligomerized polyphenol compounds are considered to be easily absorbed and have higher bioavailability than polyphenol polymers abundant in raw fruits and plants [21]. Oligonol has been reported to be safe enough for use as a dietary supplement [19] [22], while exhibiting strong antioxidant capacity [21]. The safety of Oligonol was established in studies evaluating acute and subchronic administration, as well as its genotoxicity [19]. Growing in vitro and in vivo evidence suggests that Oligonol has a number of beneficial biological effects, including amelioration of potassium bromate-induced renal toxicity in rats [21], attenuation of dysregulated expression of adipokines in adipocytes [23] and diabetic liver damage [24], inhibition of dextran sulfate-induced colitis [25], and inhibition of influenza virus proliferation [26]. These effects are believed to be related to the antioxidative activity of Oligonol. In humans, Oligonol intake was shown to reduce fatigue during exercise [27], attenuate exercise-induced increases in serum inflammatory markers such as proinflammatory cytokines and cortisol level [28], and ameliorate abdominal obesity [29].

$N$-methyl- $N$-nitrosourea (MNU), an alkylating agent, was reported to induce retinal degeneration in mice, rats, and other animals following systemic administration, providing a simple model of retinal degenerative diseases, including RP [30]. Although the exact mechanism underlying MNU-induced retinal cell death is not fully understood, oxidative stress was recently proposed to be a contributing factor [31]. The strong antioxidative activity and excellent safety profile of Oligonol provided a compelling rationale to evaluate its potential suppressive activity against MNU-induced retinal degeneration. The results show that both systemic injection and oral administration of Oligonol effectively suppress retinal degeneration in MNU-administrated mice.

\section{Materials and Methods}

\subsection{Oligonol}

Oligonol was produced by oligomerization of polyphenol polymers in the extract of lychee fruit pericarps, and is 
commercially available at present (Amino Up Chemical Co., Ltd., Sapporo). The procedure used for the production, as well as an analysis of the polyphenol composition of Oligonol, was described elsewhere [32]. Briefly, Oligonol contains 30\% - 50\% oligomeric polyphenols (component monomers of catechin and epicatechin, dimers of polycyanidins, and epicatechin trimers). Oligonol powder was dissolved in saline at a time of use.

\subsection{Mice}

Male C57BL/6 mice were purchased from Sankyo Lab Service Co., Ltd. (Tokyo, Japan). All animal experiments were performed in accordance with the Ethical Committee Guidelines for Animal Experimentation, Teikyo University.

\subsection{Reagents}

MNU (Chem Service, West Chester, PA, USA) was dissolved in $0.9 \%$ saline solution containing $0.05 \%$ acetic acid. 3-Aminobenzamide was purchased from Sigma (St. Louis, MO, USA) and dissolved in $0.9 \%$ saline. Oligonol was supplied by Amino Up Chemical Company (Sapporo, Japan) and was dissolved in $0.9 \%$ saline. Solutions of MNU, 3-aminobenzamide and Oligonol were prepared at the time of administration.

\subsection{Histological Analysis of MNU-Induced Retinal Degeneration}

Mice (7 weeks old) received single intraperitoneal (i.p.) injection of MNU (60 mg/kg) on day 0. Immediately after MNU injection and daily over the next 6 days (days 1 - 6), 10,100, and $1000 \mathrm{mg} / \mathrm{kg}$ of Oligonol was administered once daily by oral (p.o.) gavage or at a dose of $100 \mathrm{mg} / \mathrm{kg}$ by i.p injection. As a positive control, four mice were administered 3-aninobenzamide $(50 \mathrm{mg} / \mathrm{kg}$ ) by subcutaneous (s.c.) injection concurrent with the MNU treatment. In the control (untreated) group, respective vehicle solutions were administered i.p. or p.o. On day 7, mice were killed by cervical dislocation, and the eyes were quickly removed and fixed for $30 \mathrm{~min}$ in methacarn (60\% methanol, 30\% chloroform and 10\% acetyl acid). The fixed eyes (one eye per mouse) were embedded in paraffin and 7- $\mu \mathrm{m}$-thick sections were cut parallel with the maximum circumference of the eyeball through the optic disc. The sections were stained with hematoxylin and eosin (HE) and observed at $\times 100$ magnification using an Olympus BX51 light microscopy.

\subsection{Quantification of Photoreceptor Cell Loss}

To evaluate the damage of the photoreceptor cells, the photoreceptor cell ratio was calculated as [(outer retinal thickness)/(total retinal thickness)] $\times 100 \%$, as previously described [31]. Outer retinal thickness denotes the distance from the outer nuclear layer to the pigment epithelium layer. Total retinal thickness denotes the distance from the internal lining membrane to the pigment epithelium.

\subsection{TUNEL Staining}

Histochemical staining using the terminal deoxynucleotidyl-transferase (TdT)-mediated dUTP-biotin nick endlabeling (TUNEL) method was performed to detect DNA fragmentation as a marker of apoptosis [33] using a commercially available kit (In situ cell death detection kit, Roche, Mannheim, Germany). Retinal sections collected on days 1 or 2 following MNU injection from Oligonol- or vehicle-treated mice were prepared as described above. Following deparaffinization, TUNEL staining of the sections was performed according to the manufacturer's protocol.

\subsection{Detection of $\mathbf{8}-\mathbf{O H d G}$}

To examine the formation of 8-hydroxydeoxyguanosine (8-OHdG), an indicator of DNA modification by reactive oxygen species, paraffin-fixed retinal sections were deparaffinized and blocked with normal serum. Following blocking, sections were incubated with anti-8-OHdG antibody (Japan Institute for the Control of Aging, Shizuoka, Japan) overnight at $4^{\circ} \mathrm{C}$. The antibody binding was visualized using the standardavidin-biotin-alkaline phosphatase complex (ABC-AP) method (ABC-AP kit from Vector Laboratories, UK) with the Vector Red substrate (Vector Laboratories, UK). 


\subsection{Visual Cliff Test}

Gross visual activity of the mice was evaluated using a visual cliff test performed using a technique described by Krishnamoorthy et al. [34], with minor modifications. A clear glass plate $(60 \times 60 \mathrm{~cm})$ was set $1 \mathrm{~m}$ above the ground. A black-and-white checkerboard $(30 \times 30 \mathrm{~cm}$ total dimensions, with $1 \times 1 \mathrm{~cm}$ squares $)$ was placed at the center of the lower surface of the glass plate. The edge of the checkerboard represented the virtual "cliff”. To test the visual activity of mice, each mouse was placed in the center of the checkerboard, and the time spent on the checkerboard without leaving its area was recorded. Behavior was measured only for the first 60 sec, since general behavioral factors become a dominant influence affecting mouse location more than visual activity beyond that time point. Measurements were repeated on the next day by another operator, with similar results obtained.

\subsection{Statistical Analysis}

Data are expressed as means \pm standard deviations. Statistical analysis was conducted using Dunnett's test with $P<0.05$ considered statistically significant.

\section{Results}

\subsection{Suppression of MNU-Induced Photoreceptor Cell Death by Oligonol}

A single systemic injection of MNU was previously shown to induce apoptosis and a loss of photoreceptor cells within 7 days [29]. In current study, we evaluated the effect of Oligonol on the MNU-induced photoreceptor cell loss using histological analysis. Based on the results of a subchronic study that has detected no adverse effects, weight loss, or alterations in food consumption with Oligonol administration at doses up to $1000 \mathrm{mg} / \mathrm{kg}$ in rats [19], we administered Oligonol at doses of $100 \mathrm{mg} / \mathrm{kg}$ i.p. and $10-1000 \mathrm{mg} / \mathrm{kg}$ p.o. As shown in Figure 1, the outer nuclear layer (ONL) was markedly diminished, i.e. the number of nuclei and the thickness of the photoreceptor layer (PRL) were reduced on the 7th day following a single MNU injection. These observations confirm past reports of MNU-induced loss of photoreceptor cells [29]. Daily administrations of Oligonol, both by the i.p. and p.o. route, for 7 consecutive days significantly suppressed the loss of ONL and PRL.

MNU modifies DNA in the photoreceptor cell nuclei to yield a 7-methylguanosine DNA adduct, resulting in an activation of poly (ADP-ribose) polymerase (PARP), a DNA repair enzyme [29]. Since a single s.c. injection of PARP inhibitor 3-aminobenzamide was reported to inhibit MNU-induced photoreceptor cell apoptosis in rats [30], PARP activation is thought to be a key event in the apoptotic cascade in the photoreceptor cells. We examined the effect of 3-aminobenzamide as a positive control, showing that 3-aminobenzamide administration

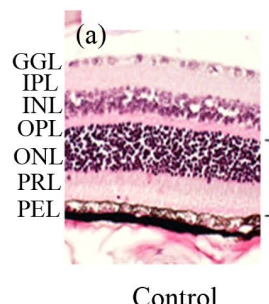

Control (b)

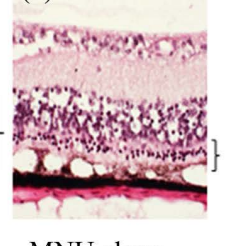

MNU alone (c)

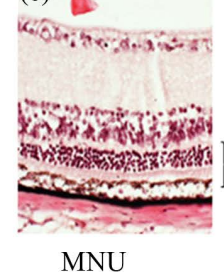

+ 3-aminobenzamide

$(50 \mathrm{mg} / \mathrm{kg}$ ) (d)

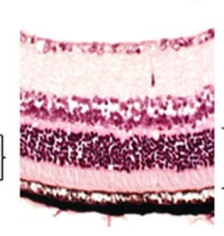

MNU

+ Oligonol

(100 mg/kg, i.p.) (e)

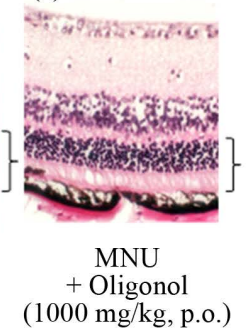

Figure 1. Histology of retina of MNU-treated mice stained by hematoxylin and eosin. C57BL/6 mice were treated with vehicle (A) or MNU (60 mg/kg) by i.p. at start of experiment (day 0; B-E). MNU-treated mice received a single s.c. injection of 3-aminobenzamide (50 mg/kg) soon after the MNU injection on day 0 (C). Oligonol $(100 \mathrm{mg} / \mathrm{kg}, \mathrm{D} ; 1000 \mathrm{mg} / \mathrm{kg}$, E) was administered daily by i.p. injection for 7 days, starting from day 0 . On day 7 , mice were sacrificed and the eyes were fixed. The sections were stained with hematoxylin and eosin. Images were obtained at $\times 200$ magnification. GCL, ganglion cell layer; IPL, inner plexiform layer; INL, inner nuclear layer; OPL, outer plexiform layer; ONL, outer nuclear layer; PRL, photoreceptor layer; PEL, pigment epithelial layer. The right parentheses indicate the outer retinal thickness, measured as the distance between the outer nuclear layer and the pigment epithelium layer. 
moderately suppressed the photoreceptor cell loss in MNU-treated mice.

To quantify the suppressive effect of Oligonol against MNU-induced photoreceptor cell loss, we calculated the ratios of the photoreceptor cell layer thickness to the total retinal thickness (Figure 2). MNU significantly reduced the photoreceptor cell layer ratio, whereas i.p. administration of $100 \mathrm{mg} / \mathrm{kg}$ Oligonol significantly atenuated MNU-induced damage to the photoreceptor cells. Since Oligonol is intended to be used as a food supplement, we examined the effectiveness of its oral administration at doses between 10 and $1000 \mathrm{mg} / \mathrm{kg}$. Suppression of the effect of MNU was observed even at the $10 \mathrm{mg} / \mathrm{kg}$ dose, with the magnitude of the effect comparable to the effect observed following 100 and $1000 \mathrm{mg} / \mathrm{kg}$ Oligonol p.o. treatments. Oligonol did not completely abolish the effects of MNU on the photoreceptor cells even at the $1000 \mathrm{mg} / \mathrm{kg}$ dose. Interestingly, 3-aminobenzamide administration marginally protected against the MNU-induced photoreceptor cell loss in this experiment, in contrast to the findings of past studies which have reported a complete suppression of the deleterious effects of MNU after a single administration of $50 \mathrm{mg} / \mathrm{kg} 3$-aminobenzamide. This discrepancy may be caused by the difference in the experimental system used, particularly the difference in the animal species; conceivably, higher doses of the agent are required to obtain a similar effect in mice as compared to rats.

To examine whether Oligonol inhibits the MNU-induced apoptosis of photoreceptor cells, retinal sections were stained by TUNEL to detect DNA fragmentation, a hallmark of apoptosis. Administration of a high dose of MNU (100 mg/kg) resulted in an increase in the number of TUNEL-positive cells in the outer nuclear layer, which includes the nuclei of photoreceptor cells, on day 2 and, more extensively, on day 3 (Figure 3, left). Oligonol treatment attenuated the MNU-induced increase in intensity of TUNEL staining on days 2 and 3, suggesting that it suppressed the induction of photoreceptor cell apoptosis by MNU.

MNU-induced oxidative stress leads to photoreceptor cell apoptosis [35]. 8-OHdG, a product of DNA oxidation, is one of the most commonly used markers of oxidative stress. MNU reportedly increases 8-OHdG levels in the outer nuclear layer of the retina $12 \mathrm{~h}$ after the i.p. injection of MNU. We detected 8-OHdG in both the outer and inner nuclear layers of MNU-treated mice, whereas no 8-OHdG was found in the retinal tissue of control (untreated) mice. Importantly, Oligonol reduced 8-OHdG levels in both layers following MNU administration, suggesting that Oligonol suppresses MNU-induced oxidative stress (Figure 3, right).

\subsection{Oligonol Rescues Loss of Visual Activity Caused by MNU}

Since Oligonol suppressed MNU-induced retinal degeneration in the histological analysis, we used the "visual

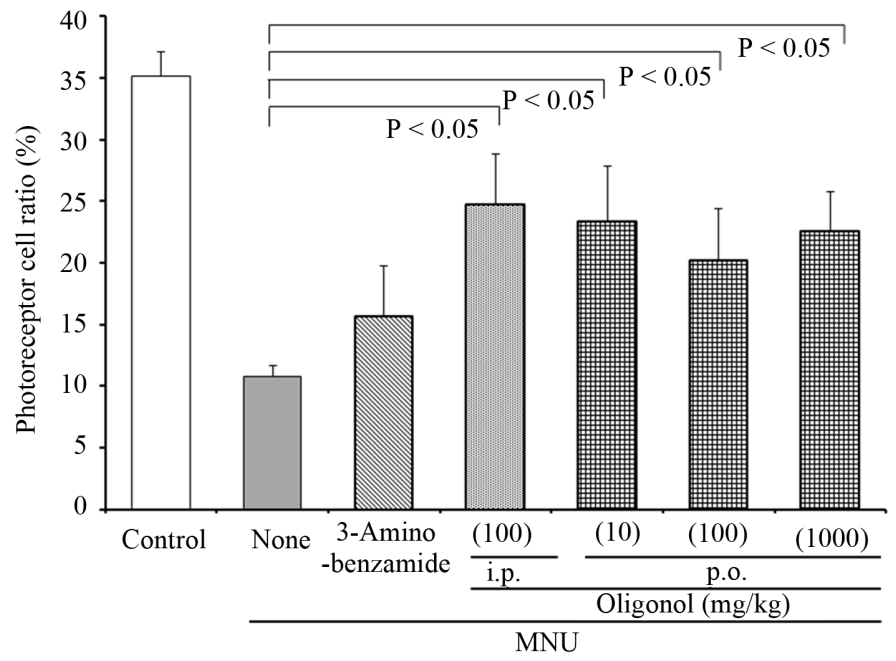

Figure 2. Suppression of MNU-induced photoreceptor cell damage by Oligonol i.p. or p.o. administration. MNU (60 mg/kg) was injected i.p. into C57BL/6 mice on day 0. Oligonol (100 mg/kg, i.p. or 10, 100, and $1000 \mathrm{mg} / \mathrm{kg}$, p.o.) was administrated on 7 consecutive days from day 0 , and 3 -aminobenzamido (50 $\mathrm{mg} / \mathrm{kg}$ ) was injected s.c. only on day $0(n=4$ for each treatment group). On day 7 , mice $(n=4)$ were sacrificed and the eyes were fixed. The loss of the photoreceptor cells on day 7 was quantified as described in Materials and Methods. 

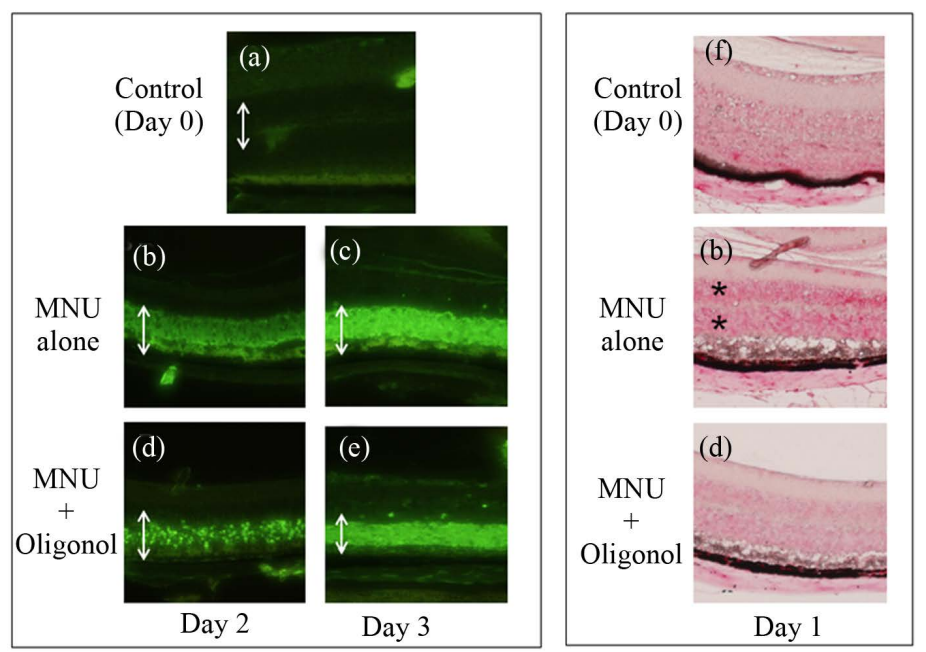

Figure 3. TUNEL stain and detection of 8-OHdG in the retinal sections of the MNU-injected mice with or without Oligonol administration. MNU (100 mg/kg) was injected i.p. on day 0. For the preparation of day 1 section, Oligonol (100 $\mathrm{mg} / \mathrm{kg}$ ) was injected i.p. on day 0 . Oligonol injection was repeated on day 1 , and on day 2 in case of the sections prepared from tissue collected on day 2 or day 3. Left; TUNEL stain. Bidirectional arrows indicate the thickness of the outer nuclear layer (ONL). Right; detection of 8-OHdG. The asterisks ( $\left(^{*}\right)$ represent 8-OHdG-positive lesions: the layers marked by the lower and upper asterisk correspond to ONL, and the inner nuclear layer (INL).

cliff test" to study whether Oligonol can reverse the MNU-induced impairment in visual activity. Animals that underwent the cliff test were administered $100 \mathrm{mg} / \mathrm{kg}$ dose of MNU. Higher dose of MNU (in comparison to the dose used in the experiments studying histological changes) was used to achieve a clear deficiency in visual activity in mice.

Mice hesitate to pass out from the central checkerboard area, because the edges are perceived as a "virtual cliff" (see Figure 4(a)). As shown in Figure 4(b), a majority of the control mice spent the entire $60 \mathrm{sec}$ of the assay on the checkerboard, while all of the MNU-treated mice exited the checkerboard during the first 15 sec. This finding clearly demonstrates the impairment of visual activity by MNU. Daily administration of Oligonol (100 mg/kg, i.p., as well as $1000 \mathrm{mg} / \mathrm{kg}$, p.o.) significantly extended the length of time that the mice spent on the checkerboard. In this experiment, the effect of 3-aminobenzamide was not significant, although the mean value of the length of time that mice treated with both MNU and 3-aminobenzamide spent on the checkerboard was higher than that of mice treated with MNU alone. This result suggests that administration of Oligonol by both i.p. and p.o. routes rescues the MNU-induced loss of visual activity.

\section{Discussion}

Photoreceptor cell death is the common pathway in RP [4]. Since MNU injection specifically induces apoptosis of retinal cells within several days in animals [30], MNU-induced retinal damage is a good model for RP. Using this model of retinal degeneration, previous studies have demonstrated retinoprotective effects of the apoptosis inhibitor 3-aminobenzamide [30], calcium antagonists nimodipine [36] and docosahexaenoic acid [37], anthocyanins extracted from black soy beans [38], nicotinamide [39], and curcumin [40]. In search of the remedy for $\mathrm{RP}$, very low toxicity is a key requirement for compounds aimed at preventing retinopathy, since retinal damage in RP patients develops through a gradual process that progresses over decades.

Oligonol is a widely available nutritional supplement with an established safety profile. The safety of Oligonol was examined in the animal acute and chronic toxicity studies [19]. In addition, supplementation of Oligonol for healthy human volunteers was carried out at doses of $100 \mathrm{mg} /$ day and $400 \mathrm{mg} /$ day for 92 days and all the biochemical parameters were within the normal range [29]. In this paper, both oral and intraperitoneal administra- 
(a)

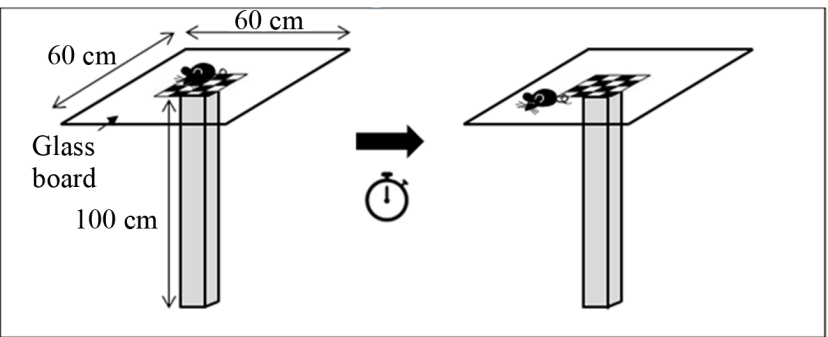

(b)

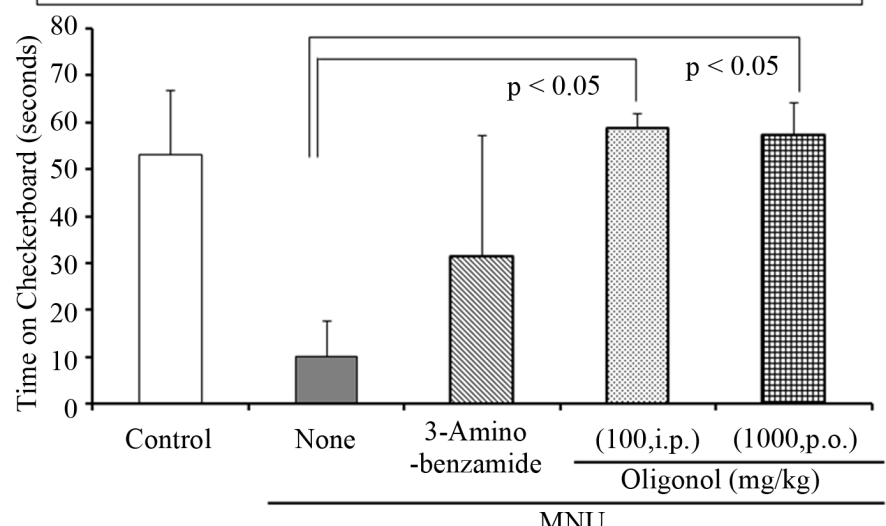

Figure 4. Estimation of the gross visual activity of mice by visual cliff test. (a) The schematic view of the apparatus used for the cliff test. (b) MNU $(100 \mathrm{mg} / \mathrm{kg})$ was administered to mice by i.p. injection on day 0 . Oligonol was administered i.p. (100 mg/kg) or p.o. (1000 mg/kg) to MNU-injected mice on 7 consecutive days, starting at day 0 . On day 10 , the visual cliff test was performed as described $(n=6)$. The length of time each mouse spent on the central checkerboard was measured for 60 sec.

tion of Oligonol suppressed MNU-induced photoreceptor cell loss as evidenced by the outcomes of the histological analysis. It is noteworthy that even the $10 \mathrm{mg} / \mathrm{kg}$ of daily oral administration exert the significant effect, since it is comparable with the expected intake in humans who use oligonol as a food supplement.

To explore the mechanism of Oligonol to suppress the MNU-induced retinal damage, we studied the effect on emergences of retinal cell apoptosis and the marker of oxidative stress. We obtained the results that Oligonol attenuated the apoptosis and the intensity of 8-OHdG, which were augmented by MNU. Although the suppression of apoptosis was not complete, it corresponds well with the observation of incomplete inhibition of MNU-induced reduction in the photoreceptor cell layer thickness by Oligonol. Although 8-OHdG was detected in both the outer and inner nuclear layer, apoptosis was only observed in the outer nuclear layer. This finding suggests that the photoreceptor cells are highly sensitive to oxidative stress. In spite of the reduction in 8-OHdG, MNUinduced apoptosis was not completely abolished by the Oligonol administration, suggesting that a mechanism other than oxidative stress contributes to the induction of photoreceptor cells apoptosis. Further experiments are warranted to identify the specific mechanism.

Using the visual cliff test, we found that Oligonol suppressed not only the loss of photoreceptor cells but also the visual activity deficit in mice treated by MNU. In the next study, a functional evaluation in MNU-treated mice with and without Oligonol administration using electroretinographic recordings would be highly informative.

Based on the findings of our current study, we propose Oligonol, a dietary supplement comprising oligomerized polyphenols as a new candidate for the treatment of RP and other retinal degenerative disease. However, comparison between Oligonol and other substances which are reportedly effective for the MNU model is required to evaluate the efficacy and the safety. In addition, a number of factors remain to be investigated before Oligonol can be recommended for application in human patients. The active ingredients of Oligonol and the exact mechanism underlying the observed protection against the MNU-induced photoreceptor cell apoptosis need to be elucidated. Furthermore the effective administration schedules should be tested. Finally, the efficacy of Oligonol in a genetically inherited mouse model of RP also needs to be clarified. 


\section{References}

[1] Hamel, C. (2006) Retinitis Pigmentosa. Orphanet Journal of Rare Diseases, 1, 40. http://dx.doi.org/10.1186/1750-1172-1-40

[2] Daiger, S.P., Sullivan, L.S. and Bowne, S. (2013) Genes and Mutations Causing Retinitis Pigmentosa. Journal of Clinical Genetics, 84, 132-141. http://dx.doi.org/10.1111/cge.12203

[3] Musarella, M.A. and Macdonald, I.M. (2011) Current Concepts in the Treatment of Retinitis Pigmentosa. Journal of Ophthalmology, 2011, Article ID: 753547. http://dx.doi.org/10.1155/2011/753547

[4] Sahni, J.N., Angi, M., Irigoyen, C., Semeraro, F., Romano, M.R. and Parmeggiani, F. (2011) Therapeutic Challenges to Retinitis Pigmentosa: From Neuroprotection to Gene Therapy. Current Genomics, 12, 276-284. http://dx.doi.org/10.2174/138920211795860062

[5] Ramsden, C.M., Powner, M.B., Carr, A.J., Smart, M.J., Da Cruz, L. and Coffey, P.J. (2013) Stem Cells in Retinal Regeneration: Past, Present and Future. Development, 140, 2576-2585. http://dx.doi.org/10.1242/dev.092270

[6] Berson, E.L., Rosner, B., Sandberg, M.A., Weigel-DiFranco, C., Moser, A., Brockhurst, R.J., Hayes, K.C., Johnson, C.A., Anderson, E.J., Gaudio, A.R., Willett, W.C. and Schaefer E.J. (2004) Further Evaluation of Docosahexaenoic Acid in Patients with Retinitis Pigmentosa Receiving Vitamin A Treatment: Subgroup Analyses. Archives of Ophthalmology, 122, 1306-1314. http://dx.doi.org/10.1001/archopht.122.9.1306

[7] Berson, E.L., Rosner, B., Sandberg, M.A., Weigel-DiFranco, C., Brockhurst, R.J., Hayes, K.C., Johnson, E.J., Anderson, E.J., Johnson, C.A., Gaudio, A.R., Willett, W.C. and Schaefer, E.J. (2010) Clinical Trial of Lutein in Patients with Retinitis Pigmentosa Receiving Vitamin A. Archives of Ophthalmology, 128, 403-411. http://dx.doi.org/10.1001/archophthalmol.2010.32

[8] Usui, S., Komeima, K., Lee, S.Y., Jo, Y.J., Ueno, S., Rogers, B.S., Wu, Z., Shen, J., Lu, L., Oveson, B.C., Rabinovitch, P.S. and Campochiaro, P.A. (2009) Increased Expression of Catalase and Superoxide Dismutase 2 Reduces Cone Cell Death in Retinitis Pigmentosa. Molecular Therapy, 17, 778-786. http://dx.doi.org/10.1038/mt.2009.47

[9] Komeima, K., Rogers, B.S., Lu, L. and Campochiaro P.A. (2006) Antioxidants Reduce Cone Cell Death in a Model of Retinitis Pigmentosa. Proceedings of the National Academy of Sciences of the United States of America, 103, 1130011305. http://dx.doi.org/10.1073/pnas.0604056103

[10] Lee, S.Y., Usui, S., Zafar, A.B., Oveson, B.C., Jo, Y.J., Lu, L., Masoudi, S. and Campochiaro, P.A. (2011) N-Acetylcysteine Promotes Long-Term Survival of Cones in a Model of Retinitis Pigmentosa. Journal of Cellular Physiology, 226, 1843-1849. http://dx.doi.org/10.1002/jcp.22508

[11] Leonard, K.C., Petrin, D., Coupland, S.G., Baker, A.N., Leonard, B.C., LaCasse, E.C., Hauswirth, W.W., Korneluk, R.G. and Tsilfidis C. (2007) XIAP Protection of Photoreceptors in Animal Models of Retinitis Pigmentosa. PLoS ONE, 2, e314. http://dx.doi.org/10.1371/journal.pone.0000314

[12] Gryglewski, R.J., Korbut, R., Robak, J. and Świẹs, J. (1987) On the Mechanism of Antithrombotic Action of Flavonoids. Biochemical Pharmacology, 36, 317-322. http://dx.doi.org/10.1016/0006-2952(87)90288-7

[13] Middleton Jr., E. and Kandaswami, C. (1992) Effects of Flavonoids on Immune and Inflammatory Cell Functions. Biochemical Pharmacolology, 43, 1167-1179. http://dx.doi.org/10.1016/0006-2952(92)90489-6

[14] Havsteen, B.H. (2002) The Biochemistry and Medical Significance of the Flavonoids. Pharmacology and Therapeutics, 96, 67-202. http://dx.doi.org/10.1016/S0163-7258(02)00298-X

[15] Ueda, H., Yamazaki, C. and Yamazaki, M. (2004) A Hydroxyl Group of Flavonoids Affects Oral Anti-Inflammatory Activity and Inhibition of Systemic Tumor Necrosis Factor-Alpha Production. Bioscience, Biotechnology, and Biochemistry, 68, 119-125. http://dx.doi.org/10.1271/bbb.68.119

[16] Soobrattee, M.A., Bahorun, T. and Aruoma, O.I. (2006) Chemopreventive Actions of Polyphenolic Compounds in Cancer. BioFactors, 27, 19-35. http://dx.doi.org/10.1002/biof.5520270103

[17] Bagchi, D., Garg, A., Krohn, R.L., Bagchi, M., Bagchi, D.J., Balmoori, J. and Stohs, S.J. (1998) Protective Effects of Grape Seed Proanthocyanidins and Selected Antioxidants against TPA-Induced Hepatic and Brain Lipid Peroxidation and DNA Fragmentation, and Peritoneal Macrophage Activation in Mice. General Pharmacology: The Vascular System, 30, 771-776. http://dx.doi.org/10.1016/S0306-3623(97)00332-7

[18] Santos-Buelga, C. and Scalbert, A. (2000) Proanthocyanidins and Tannin-Like Compounds-Nature, Occurrence, Dietary Intake and Effects on Nutrition and Health. Journal of the Science of Food and Agriculture, 80, 1094-1117. http://dx.doi.org/10.1002/(SICI)1097-0010(20000515)80:7<1094::AID-JSFA569>3.0.CO;2-1

[19] Fujii, H., Nishioka, H., Wakame, K., Magnuson, B.A. and Roberts, A. (2008) Acute, Subchronic and Genotoxicity Studies Conducted with Oligonol, an Oligomerized Polyphenol Formulated from Lychee and Green Tea Extracts. Food and Chemical Toxicology, 46, 3553-3562. http://dx.doi.org/10.1016/i.fct.2008.06.005

[20] Tanaka, T., Yoshitake, N., Zhao, P., Matsuo, Y., Kouno, I.L. and Nonaka, G.I. (2007) Production of Oligometric Pro- 
antocyanidins by Fragmentation of Polymers. Japanese Journal of Food Chemistry, 14, 134-139.

[21] Nishioka, H., Fujii, H., Sun, B. and Aruoma, O.I. (2006) Comparative Efficacy of Oligonol, Catechin and (-)-Epigallocatechin 3-O-Gallate in Modulating the Potassium Bromate-Induced Renal Toxicity in Rats. Toxicology, 226, 181187. http://dx.doi.org/10.1016/j.tox.2006.06.017

[22] Fujii, H., Sun, B., Nishioka, H., Hirose, A. and Aruoma, O.I. (2007) Evaluation of the Safety and Toxicity of the Oligomerized Polyphenol Oligonol. Food and Chemical Toxicology, 45, 378-387. http://dx.doi.org/10.1016/j.fct.2006.08.026

[23] Sakurai, T., Nishioka, H., Fujii, H., Nakano, N., Kizaki, T., Radak, Z., Izawa, T., Haga, S. and Ohno, H. (2008) Antioxidative Effects of a New Lychee Fruit-Derived Polyphenol Mixture, Oligonol, Converted into a Low-Molecular Form in Adipocytes. Bioscience, Biotechnology, and Biochemistry, 72, 463-476. http://dx.doi.org/10.1271/bbb.70567

[24] Noh, J.S., Park, C.H. and Yokozawa, T. (2011) Treatment with Oligonol, a Low-Molecular Polyphenol Derived from Lychee Fruit, Attenuates Diabetes-Induced Hepatic Damage through Regulation of Oxidative Stress and Lipid Metabolism. British Journal of Nutrition, 106, 1013-1022. http://dx.doi.org/10.1017/S0007114511001322

[25] Yum, H.W., Zhong, X., Park, J., Na, H.K., Kim, N., Lee, H.S. and Surh, Y.J. (2013) Oligonol Inhibits Dextran Sulfate Sodium-Induced Colitis and Colonic Adenoma Formation in Mice. Antioxidants and Redox Signaling, 19, 102-114. http://dx.doi.org/10.1089/ars.2012.4626

[26] Gangehei, L., Ali, M., Zhang, W., Chen, Z., Wakame, K. and Haidari, M. (2010) Oligonol a Low Molecular Weight Polyphenol of Lychee Fruit Extract Inhibits Proliferation of Influenza Virus by Blocking Reactive Oxygen SpeciesDependent ERK Phosphorylation. Phytomedicine, 17, 1047-1056. http://dx.doi.org/10.1016/j.phymed.2010.03.016

[27] Ohno, H., Sakurai, T., Hisajama, T., Abe, S., Kizaki, T., Ogasawara, J.E., Ishibashi, Y., Imaizumi, K., Takemasa, T., Haga, S., Kitadate, K., Nishioka, H. and Fujii, H. (2008) The Supplementation of Oligonol, the New Lychee Fruit-Derived Polyphenol Converting into a Low-Molecular Form, Has a Positive Effect on Fatigue during Regular Track-andField Training in Young Athletes. Advances in Exercise and Sports Physiology, 13, 93-99.

[28] Lee, J.B., Shin, Y.O., Min, Y.K. and Yang, H.M. (2010) The Effect of Oligonol Intake on Cortisol and Related Cytokines in Healthy Young Men. Nutrition Research and Practice, 4, 203-207. http://dx.doi.org/10.4162/nrp.2010.4.3.203

[29] Nishihira, J., Sato-Ueshima, M., Kitadate, K., Wakame, K. and Fujii, H. (2009) Amelioration of Abdominal Obesity by Low-Molecular-Weight Polyphenol (Oligonol) from Lychee. Journal of Functional Foods, 1, 341-348. http://dx.doi.org/10.1016/j.jff.2009.09.002

[30] Tsubura, A., Lai, Y.C., Miki, H., Sasaki, T., Uehara, N., Yuri, T. and Yoshizawa, K. (2011) Animal Models of N-Methyl-N-Nitrosourea-Induced Mammary Cancer and Retinal Degeneration with Special Emphasis on Therapeutic Trials. In Vivo, 25, 11-22.

[31] Miki, K., Uehara, N., Shikata, N., Matsumura, M. and Tsubura, A. (2007) Poly (ADP-Ribose) Polymerase Inhibitor 3-Aminobenzamide Rescues N-Methyl-N-Nitrosourea-Induced Photoreceptor Cell Apoptosis in Sprague-Dawley Rats through Preservation of Nuclear Factor-kB Activity. Experimental Eye Research, 84, 285-292. http://dx.doi.org/10.1016/j.exer.2006.09.023

[32] Miura, T., Kitadate, K. and Fujii, H. (2010) The Function of the Next Generation Polyphenol, “Oligonol”. In: Bagchi, D., Lau, F.C. and Ghosh, D.K., Eds., Biotechnology in Functional Foods and Nutraceuticals, CRC Press, Boca Raton, 91-102.

[33] Gavrieli, Y., Sherman, Y. and Ben-Sasson, S.A. (1992) Identification of Programmed Cell Death in Situ via Specific Labeling of Nuclear DNA Fragmentation. Journal of Cell Biology, 119, 493-501. http://dx.doi.org/10.1083/jcb.119.3.493

[34] Krishnamoorthy, V., Jain, V., Cherukuri, P., Baloni, S. and Dhingra, N.K. (2008) Intravitreal Injection of Fluorochrome-Conjugated Peanut Agglutinin Results in Specific and Reversible Labeling of Mammalian Cones in Vivo. Investative Ophthalmology and Visual Science, 49, 2643-2650. http://dx.doi.org/10.1167/iovs.07-1471

[35] Tsuruma, K., Yamauchi, M., Inokuchi, Y., Sugitani, S., Shimazawa, M. and Hara, H. (2012) Role of Oxidative Stress in Retinal Photoreceptor Cell Death in N-Methyl-N-Nitrosourea-Treated Mice. Journal of Pharmacological Sciences, 118, 351-362. http://dx.doi.org/10.1254/jphs.11110FP

[36] Wang, D., Li, Y., Wang, Z., Sun, G.Y. and Zhang, Q.H. (2013) Nimodipine Rescues N-Methyl-N-Nitrosourea-Induced Retinal Degeneration in Rats. Pharmacognosy Magazine, 9, 149-154. http://dx.doi.org/10.4103/0973-1296.111276

[37] Moriguchi, K., Yuri, T., Yoshizawa, K., Kiuchi, K., Takada, H., Inoue, Y., Hada, T., Matsumura, M. and Tsubura, A. (2003) Dietary Docosahexaenoic Acid Protects against N-Methyl-N-Nitrosourea-Induced Retinal Degeneration in Rats. Experimental Eye Research, 77, 167-173. http://dx.doi.org/10.1016/S0014-4835(03)00114-3

[38] Paik, S.S., Jeong, E., Jung, S.W., Ha, T.J., Kang, S., Sim, S., Jeon, J.H., Chun, M.H. and Kim, I.B. (2012) Anthocyanins from the Seed Coat of Black Soybean Reduce Retinal Degeneration Induced by N-Methyl-N-Nitrosourea. Experimental Eye Research, 97, 55-62. http://dx.doi.org/10.1016/j.exer.2012.02.010 
[39] Kiuchi, K., Yoshizawa, K., Shikata, N., Matsumura, M. and Tsubura, A. (2002) Nicotinamide Prevents N-Methyl-NNitrosourea-Induced Photoreceptor Cell Apoptosis in Sprague-Dawley Rats and C57BL Mice. Experimental Eye Research, 74, 383-392. http://dx.doi.org/10.1006/exer.2001.1127

[40] Emoto, Y., Yoshizawa, K., Uehara, N., Kinoshita, Y., Yuri, T., Shikata, N. and Tsubura, A. (2013) Curcumin Suppresses N-Methyl-N-Nitrosourea-Induced Photoreceptor Apoptosis in Sprague-Dawley Rats. In Vivo, 27, 583-590. 